\title{
A EXPERIÊNCIA DA \\ INTERAÇÃO E O DESIGN DE \\ INTERFACES: SEMIÓTICA E \\ METACOMUNICAÇÃO NOS DIGITAL \\ AUDIO WORKSTATIONS
}

\section{THE INTERACTION AND THE INTERFACES DESIGN EXPERIENCES: SEMIOTICS AND METACOMMUNICATION IN THE DIGITAL AUDIO WORKSTATIONS}

RODRIGO FONSECA E RODRIGUES*

ANA MARIA PEREIRA CARDOSO**

RESUMO: 0 artigo levanta alguns problemas relacionados à concepção de interfaces para os Digital Audio Workstations (DAWs). A abordagem teórica utiliza os conceitos de semiose e das três fases da experiência da Semiótica peirceana. A tese da metacomunicação, apresentada pela Engenharia Semiótica, também é estudada e se refere à singularidade do diálogo entre designers e usuários. Como consequência, diferentes

\footnotetext{
* Docente da FUMEC - Universidade Fundação Mineira de Educação e Cultura. Email: rfonseca@fumec.br .

** Docente da FUMEC - Universidade Fundação Mineira de Educação e Cultura. Email: ana.cardoso@fumec.br .
} 
estratégias de comunicação são requeridas, levando-se em conta que tal conversação não ocorre num tempo sincrônico. Os DAWs Sonar (CakeWalk, 2010) e o GarageBand (Apple, 2013) foram eleitos como corpus empírico porque seus projetos almejam balancear a performance do sistema com as habilidades mnemônicas e intuitivas sob diferentes arquétipos culturais, técnicos e afetivos de seus potenciais utilizadores: pessoas com expectativas singulares diante de um dispositivo de gravação sonora. Acredita-se que as concepções do design, além de perseguirem novas funcionalidades, poderiam procurar oferecer aos usuários dos DAWs possibilidades de exploração do sistema a partir de suas próprias performances regulares. Desse modo, o compositor seria convidado a repensar seus métodos de criação musical e suas singularidades insuspeitadas de escuta.

PALAVRAS-CHAVE: Design de interação. Interfaces digitais. Metacomunicação. Experiência do usuário. Digital Audio Workstation.

ABSTRACT: The paper raises some problems related to the conception ofinterfaces for Digital Audio Workstations (DAWs). The theoretical approach uses the concept of semiosis and the three phases of the experience from Peirce's Semiotics. The thesis of the metacommunication presented by Semiotics Engineering is also studied and refers to the singularity of the dialogue between designers and users. As a consequence, different strategies of communication are required, taking into account that their conversation takes place in an asynchronic time. The DAWs Sonar (CakeWalk, 2010) and GarageBand (Apple, 2013) were elected as empirical corpus because their projects aim to balance the performance of the system with 
the intuitions and memory abilities under different cultural, technical, affective archetypes of their potential users: people with singular expectations about the sound recorder device. One believes that design conceptions, beyond pursuing new functionalities, could try to offer the DAW's users possibilities of exploration of the system inside its regular performances. Thus, the composer would be invited to rethink their methods of musical creation and non-assumed singularities of listening.

KEYWORDS: Interaction design. Digital interfaces. Metacommunication. User's experience. Digital Audio Workstation.

\section{Introdução}

Os aperfeiçoamentos tecnológicos dos estúdios digitais de gravação, edição, mixagem, equalização e masterização de áudio observados desde os anos 1980, inicialmente acoplados a teclados sintetizadores ou sob a forma de módulos chamados de sequencers, alcançaram o formato de softwares conectados a computadores pessoais a partir de 1994, denominados como Digital Audio Workstation. Esses estúdios atingiram não somente um nível técnico de performance sonora, mas caminharam em paralelo com o desenvolvimento de suportes de interface e interação para controles que atualmente superam, em certos aspectos, os dispositivos analógicos preexistentes. Com a consequente adesão de compositores, instrumentistas, designers sonoros, engenheiros de som, DJs e músicos amadores aos DAWs, a acessibilidade, tanto econômica quanto técnica expandiu-se, estendendo a sua aplicação a praticamente todos os ramos da criação musical, tais como as trilhas sonoras do cinema, a publicidade, o design sonoro, 
bem como a indústria fonográfica e o audiovisual midiático.

Este artigo aborda, especificamente, questões que designers dos DAWs encontram no processo de concepção, prototipação, realização e aperfeiçoamento de interfaces pelas quais o utilizador experimenta o processo de composição, registro, montagem, finalização sonora e musical. Todo o empenho de tornar a experiência a mais otimizada possível e minimamente frustrante requer um esforço de idealização que deve levar em conta, além do universo da escuta e da performance criativa musicais, os hábitos mnemônicos, sensitivos, afetivos, gestuais e ergonométricos. 0 principal dilema entre os projetos de DAW é, por um lado, oferecer o melhor desempenho possível, o que envolve grande especialização técnica em suas ações e, por outro lado, apresentar uma interface mais intuitiva. Este breve estudo se pauta num exercício de comparação entre dois modelos conceituais de interação e de performance para projetos de DAW distintos - Sonar (CalkeWalk, 2010) e GarageBand (Apple, 2013) - procurando interpretar as soluções apresentadas pelos seus desenvolvedores no design de interface para a manutenção ou a otimização da performance fundamental do dispositivo, assim como a diminuição das dificuldades para os utilizadores.

\section{A metacomunicação do design de interfaces e a experiência na interação digital}

A utilização plena de um artefato é atravessada por um processo implícito: a forma sensível e inteligível pela qual quem o utiliza o percebe como uma experiência satisfatória em seus meios e fins. Tratam-se especialmente de hábitos de memória, expectativas, regimes da percepção, valores culturais, compe- 
tências de linguagem e de criatividade. Com efeito, quando lidamos com quaisquer dispositivos, estamos implicitamente condicionados pelo ambiente cultural, linguístico, por apelos emocionais e senso estético, em síntese, pela nossa experiência. Historicamente, na interação com os artefatos técnicos, as pessoas formam abstrações de si mesmas, do outro e das coisas com as quais estão a lidar. Essas abstrações fornecem subsídios conceituais para o entendimento das interferências da experiência nos modos de interação. Tal fato coloca dilemas, inquietações, dúvidas, experimentações e aplicações de paradigmas, sejam para os desenvolvedores de dispositivos, sejam para seus utilizadores. Há, no caso específico da experiência com interfaces digitalizadas, uma sequência de fluxos temporais que se estabilizam pelos hábitos culturais. E o design de interação é um projeto de produtos que se revelam com o tempo. Por isso o esforço do designer de interfaces visa a aproveitar a experiência mnemônica e sensitiva, o conhecimento que as pessoas têm do ambiente físico e de suas ações cotidianas. 0 designer procura, então, por meio do modelo conceitual, relacionar experiências concretas do mundo físico com abstrações, tais como representações externas, regras, convenções, comunicação verbal e não verbal utilizadas para coordenar as atividades em jogo. Como apresentado por Steinert (2010), a interface física caminha em conjunto com a interface cognitiva, ou seja, o usuário tem em mente um modelo de execução da tarefa a ser realizada para alcançar seus objetivos por meio da manipulação do artefato. Assim, a manipulação depende da interface física explicitada pelo modelo conceitual do designer, de forma a transmitir uma sensação de confiança e previsibilidade para as ações do usuário.

Em tempos de onipresente comunicação on-line, interfaces com máquinas virtuais, de convivência entre os tradicio- 
nais meios de comunicação de massa e as recentes tecnologias interativas, estudos semióticos mais singularizados surgem no cenário das ciências sociais aplicadas e humanas. É para tentar apreender os processos de percepção, significação, experiência, linguagem e comunicação que a Engenharia Semiótica (DE SOUZA, 2005) se dedica aos problemas do design de interfaces, das hipermídias e dos ambientes virtuais.

0 estudo da semiótica nos permite captar tanto os vetores de significação num contexto mais contingencial (a sensação de prazer que envolve atenção, ritmo, jogo, interatividade, envolvimento e estilo de narrativa), quanto em contextos expandidos (como a história, a cultura, instituições, técnicas, mentalidade). Uma das metas da semiótica seria examinar a natureza e o poder de referência dos signos, que informações eles trazem, como se estruturam em sistemas, como funcionam, que efeitos surtem sobre a percepção, memória, sensações, enfim, como se constrói a experiência.

O designer constrói, objetos semióticos de natureza computacional e virtual, diferentes dos objetos físicos ${ }^{1}$, ainda que a eles referidos. Projetar uma experiência bem-sucedida com artefatos digitais requer que o designer considere cada ação, cada resposta do sistema e cada signo em jogo, seja verbal ou visual, silencioso ou audível, estático ou dinâmico. Aqui a abordagem da Engenharia Semiótica pode trazer um suporte epistemológico para o design, a começar com a exploração da inter-relação de sistemas de signos que perten-

1 As interfaces digitais compreendem, como se sabe, vários tipos de sensorialidade: tátil, auditiva, visual, verbal ou a combinação de todos (háptica). Para Mireille Buydens (1990), existe um modo háptico de audição musical, que se processa pelo tato. Assim, o ouvido pode distinguir formas, cores, tatear as texturas sonoras ou entrecruzar sentidos diferentes. Aloïs Riegl defende, por seu turno, uma tactividade da visão. Para o pensamento filosófico de Gilles Deleuze (ambos citados por FERRAZ, 1998), o termo "háptico" acolhe funções que transbordam a especificidade atribuída pela fisiologia a cada sentido. 
cem à cultura dos usuários com os quais os designers almejam comunicar. A significação na experiência com os dispositivos virtuais é o processo pelo qual sistemas de signos são estabelecidos pelas convenções adotadas pelos usuários, que são igualmente intérpretes e produtores de tais signos. A maneira como se projetam interfaces de um produto interativo digital não deve entrar em conflito com os processos semiósicos, como atenção, memorização e expectativas de quem o utiliza na realização das suas tarefas, uma vez que tais processos envolvem uma experiência mediada por signos. É preciso, então, compreender tanto os processos semiósicos nos quais imagens analógicas, indiciais e simbolismos são ativados, como as ações intuitivas na interação com o sistema².

A dimensão que norteia fundamentalmente o pacto entre quem faz e quem usufrui do artefato digital é um modo singular de comunicação, ora explícita, ora implícita, mas sempre em tempos assíncronos e lugares dispersos e ignorados por cada um dos envolvidos nesse processo de criação e de experiência. Na interação entre usuários e tecnologias há

2 Para a Semiótica peirceana (PEIRCE, 1987), o signo, dependendo da sua natureza e do seu potencial, tanto pode ser uma representação mental quanto uma experiência ou mesmo uma mera qualidade de sensação. 0 significado de um signo, por seu turno, é sempre outro signo, seja este uma imagem mental, uma rememoração ou uma percepção sensorial, uma ação ou um gesto, uma palavra solta ou uma ideia concebida. Como se sabe, há para Peirce três naturezas de signos: ícone, índice e símbolo. Os signos icônicos são qualidades que representam o objeto em seu caráter qualitativo (cores, luminosidade, volumes, textura, formas) e possuem efeito de impressão análogo ao do objeto representado. 0 índice, por sua vez, é sempre dual, estabelece a ligação de uma coisa com outra por indução. 0 índice representa ou evoca, tem relação direta com o objeto que assinala, por contiguidade, uma parte de suas características, sugerindo a totalidade do objeto em questão. Quando o signo é convenção ou pacto coletivo e determina que aquele signo represente seu objeto, mesmo que este não resguarde nenhuma semelhança icônica ou referência indicial com o objeto, é chamado de símbolo. As palavras são exemplos desses signos simbólicos. 0 símbolo é um signo que representa o objeto de maneira arbitrária, por convenção e aprendizado. Os símbolos, entretanto, trazem embutidos em si caracteres icônicos e indicais. Por seu turno, ícones e índices podem remeter a signos simbolicamente convencionados. 
significações presentes que ora direcionam, ora constrangem o entendimento de um sistema ou de uma interface em particular. 0 designer seria, nesse processo, um tipo de narrador que não usa o discurso verbal para alcançar o seu interlocutor. Ele só pode usar a habilidade para se expressar através dos dispositivos interativos nos quais trabalha. E o fato mais intrigante nesse processo em que o criador da interface conta uma narrativa singular é o lugar de protagonista do utilizador, previamente condicionado por uma experiência, já frequentador de outras tantas mídias e inserido em um vasto sistema cultural (diegese ${ }^{3}$ ). A todo usuário, portanto, cabe interpretar as informações diversificadas que os desenvolvedores utilizam para construir os sistemas digitais. Quando entramos em comunicação com a interface, tornamo-nos um intérprete que representa o seu papel com um arquétipo mental sobre como os artefatos dessa natureza devem funcionar.

Todo design, mesmo não sendo especificamente de interfaces digitais é, de certa maneira, uma efetiva conversação entre todos os especialistas envolvidos na sua realização e o utilizador. Esse processo requer envolvimento de todos os atores, mas o caminho é quase sempre indeterminado e cheio de ambiguidades interpretativas. É um processo negociado pelas necessidades e intenções dos atores. 0 problema reside justamente no fato de que o designer não está mais presente quando o usuário entra em cena, e ambos só interagem por via do produto em si mesmo. Essa comunicação singular pre-

3 0 processo de interatividade não se deixa decifrar apenas pelo próprio desfile das cores, palavras, dos signos em geral, pois também é feito de anúncios, lembranças, correspondências, deslocamentos temporais. É ao que se denomina com a palavra grega diegese. Trata-se do mundo verossímil de motivações no qual se inscreve uma narração. 0 universo diegético é tudo o que uma narrativa evoca ou provoca para o espectador, a série das ações e o seu contexto, seja geográfico, histórico ou social. É, por fim, um dispositivo de interação que conta uma história, situando-a num certo universo imaginário que se materializa pelos signos da interface. 
cisa se efetivar por meio de um sistema de abstrações, como inferências, induções e deduções. Trata-se de um processo que ocorre através da interface e do comportamento do sistema. Os sistemas, de fato, falam por seus designers, pois comunicam a sua visão sobre quem são os potenciais usuários, o que desejam ou precisam fazer, de que forma e por quê. A performance interativa projetada pelos designers explora várias estratégias de comunicação direcionadas aos usuários e que deverão ser utilizadas na interação destes com o sistema. As formas de interlocução se realizam como uma espécie de comunicação sobre os próprios modos de comunicação implícitos. Tal processo é o que se designa como metacomunicação: uma performance de comunicação entre dois agentes que também comunicam algo sobre a comunicação em si mesma. Por conseguinte, as ferramentas digitais são entendidas como artefatos que dependem da metacomunicação. Por muitos meios diretos e indiretos, os designers dizem aos usuários como eles podem ou devem interagir com o sistema, para atingir seus objetivos, que são antecipados durante a concepção e prototipação do artefato.

\section{Os modelos conceituais para as interfaces digitais}

O processo de realização de um software ou aplicativo consiste basicamente em converter informações digitalizadas em um produto que será apropriado pelo usuário como um artefato físico. Ao integrar várias combinações de tecnologias computacionais, o designer busca também pensar novas formas de lidar com a multiplicidade de escolhas e decisões com as quais ele se depara quando desenvolve produtos interati- 
vos. A partir daí, é preciso entender as singularidades implícitas nas atividades ligadas à interação com produtos digitais e criar dispositivos que capitalizem a experiência prévia com os artefatos físicos quando se interage com um sistema digital. Normalmente, as inovações surgem de enxertos de ideias de aplicações diferentes, da evolução de um produto por meio do uso e da observação, ou da simples cópia de produtos semelhantes. Há, no entanto, uma relação entre a concepção do modo de como o sistema deve trabalhar, como este realmente trabalha e como o utilizador entende a performance desse sistema. Para dar conta dessa condição inicial, estabeleceram-se dois paradigmas de design: o conceitual e o físico. 0 primeiro ocupa-se de desenvolver um modelo conceitual que capte o que o produto irá realizar e como irá se comportar. Um modelo conceitual é, em outros termos, uma narração que põe a operar um sistema num contexto. Consiste em instruir a respeito de como o utilizador irá conversar, manipular, navegar, explorar e pesquisar um dispositivo, provendo razões para o seu entendimento.

Há, de acordo com Preece, Rogers e Sharp (2005), dois tipos de modelos conceituais: os pautados em atividades e aqueles baseados em objetos. 0 modelo apoiado em atividades procura tirar proveito da experiência do usuário com tarefas em mídias já conhecidas, buscando uma combinação de conhecimento familiar e conhecimento novo. Assim, são proporcionadas facilidades que permitem aos usuários saber onde se encontram. Os modelos conceituais baseados em objetos buscam fazer analogias com algo do mundo físico. Para alguns designers, um projeto bem-sucedido é aquele que se parece com algo, que nos remete a algo, que se refere a coisas do ambiente cultural mais amplo. Esses modelos conceituais são as chamadas metáforas de interface, que combinam o 
conhecimento familiar dos objetos físicos e das gestualidades envolvidas na experiência de sua manipulação com novos conceitos específicos da interface digital. Nesse caso, interfaces visuais são conceitualizadas como affordances percebidas ou convenções aprendidas ${ }^{4}$. 0 trabalho de design busca, então, emular, no mundo digital, as estratégias e os métodos que as pessoas utilizam no mundo físico, de modo a tirar proveito dessas estratégias para lidar com a realidade. Um designer, no entanto, pode reparar em algo que as pessoas fazem no mundo físico e cair na armadilha de tentar fazer o mesmo no mundo eletrônico, sem pensar em como e se isso irá funcionar num outro contexto.

As metáforas podem, em certos casos, limitar a imaginação do designer na hora de evocar novos paradigmas e modelos, porque podem se fixar em ideias surradas, restringindo, muitas vezes, o seu raciocínio a respeito de funcionalidades diferentes que poderiam ser oferecidas. Às vezes, pode ser um equívoco se pensar que objetos virtuais devem ser projetados com semelhanças com objetos físicos, porque as pessoas sabem intuitivamente como interagir com eles. Quanto mais parecido com o mundo real, mais abarrotada e difícil de utilizar poderá ser a interface. De fato, os objetos virtuais possuem propriedades um tanto diferentes das de objetos físicos (por exemplo, um botão de potenciômetro). Um objeto virtual com um ícone convida ao clique apenas porque o usuário aprendeu que o elemento gráfico na tela constitui uma representação que, quando clicada, faz alguma coisa acontecer. 0 fundamental é entender realmente a natureza do problema abordado no mundo eletrônico, com relação às várias estratégias para emular o que as pessoas desenvolveram a fim de lidar com o

4 Affordance significa um atributo de um objeto físico que permite às pessoas intuir a respeito de como utilizá-lo. 
mundo físico. Como o mapeamento entre uma representação virtual e seu comportamento é arbitrário, o usuário terá de reaprender convenções novas, estabelecidas pelo projeto de interface.

0 design físico envolve considerar questões mais concretas e detalhadas acerca do projeto, como o layout da tela ou do teclado, quais ícones e gráficos utilizar, como estruturar menus, dispor modos de ocorrência de cores, sons e imagens. Nessa fase, o designer se preocupa em como dar forma, como representar, como concretizar a ideia da interface, levando em conta a capacidade de o utilizador visualizar coisas, enfim, o quanto se consegue colocar na tela. Para tanto, é necessário identificar como as informações mais importantes e as funções serão divididas ou distribuídas nos displays. É importante encontrar um equilíbrio entre o apelo estético e a quantidade de informação $0^{5}$.

O desenvolvimento da interface precisa contar, enfim, com a relevância das habilidades e do conhecimento prévios do usuário. Um usuário pode ser novato, especialista ou casual. Essas distinções afetam as maneiras pelas quais se realiza o design de interação. 0 designer deve então imaginar, com base em técnicas e procedimentos padronizados - como

5 Nesta fase da concepção, ele deve buscar permitir tarefas simples mediante um número mínimo de passos, estabelecendo maneiras de interagir com um sistema (menus, comandos, formulários, ícones etc.). As interfaces são construídas usualmente por elementos como caixas de diálogos, menus, ícones, barras de ferramentas etc. 0 design do menu requer, por exemplo, opções relacionadas a um comando, ou seja, à estrutura da tarefa e a informação necessária para realizá-la. Nesse conjunto de procedimentos estão compreendidas a eficácia, a segurança, a utilidade, a capacidade de favorecer a aprendizagem e a memorização. Quando não estamos certos do que estamos procurando, podemos não atentar para itens salientes. Um projeto também pode oferecer templates que podem ser adaptados, pois os usuários tendem a se lembrar de operações frequentemente utilizadas. Os guidelines são outro modo estratégico de se projetar a tela de forma que a atenção do usuário seja imediatamente dirigida a pontos importantes. Deve-se observar também o preceito da "viscosidade", que significa quanto trabalho extra se tem de fazer caso o utilizador mude de ideia. 
construção de cenários ou personas -, quem são os utilizadores e o que eles querem alcançar. Os exemplos de DAWs que abordaremos como pretexto empírico para a discussão trazem pontualmente esta questão: as concepções de design que levam em conta a experiência e as expectativas singulares dos seus potenciais utilizadores.

\section{As interfaces digitais e a experiência de interação com os DAWs}

O Digital Audio Workstation é um dispositivo que tem a finalidade de gravar, editar, tocar, mesclar, equalizar e masterizar informações de áudio. Baseado em microprocessadores, evoluiu para o formato de software, rodando em computadores pessoais ${ }^{6}$. O DAW integrado consiste em um console de mixagem, superfície de controles e comandos, conversor de áudio e estoque de dados num único dispositivo. Sua interface visual, como apresentado no exemplo da imagem 1, emula a mesa de som de um estúdio de gravação analógico multipistas tradicional, comportando gravações musicais, escritas de partituras, composições, edições para trilhas sonoras de cinema ${ }^{7}$. Orquestras, grupos musicais ou quaisquer instrumentos são

6 Um software DAW mais simples atualmente pode ser transposto para outro formato, reduzido, por exemplo, para games ou web streaming, podendo também ser baixado on-line. Já se encontram igualmente no mercado os smartphone-based DAWs, chamados de Mobile Audio Workstation (MAWs)

7 Um exemplo interessante são as gravações Foley. Os designers sonoros empregam essa técnica cujo nome veio por causa de Jack Foley, editor de som da Universal Studios. Ele criou o método de regravar os sons das cenas para incrementar a qualidade sonora de filmes. A sua técnica visava a reproduzir sincronicamente, em estúdio, todo o som gerado pela atividade física dos personagens, por meio de uma mímica dos movimentos (ações imitadas pelos artistas de foley, os walkers), capturados por microfonistas ou técnicos de som, enquanto assistem as cenas. Geralmente, eles trabalham em dupla, um walker, que imita os gestos, e um técnico, que capta cuidadosamente o áudio. 
geralmente gravados e posteriormente editados, misturados e masterizados em DAWs com extrema qualidade sonora e acurada intervenção técnica sobre o material acústico.

Imagem 1 - Interface visual do DAW CakeWalk

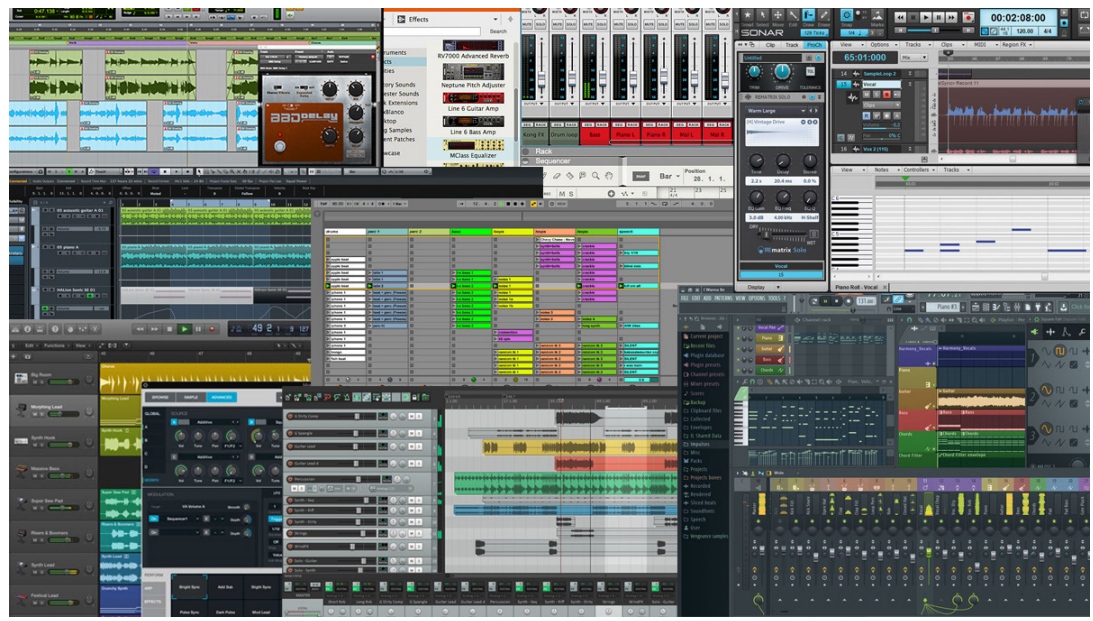

Fonte: CakeWalk (www.cakewalk.com) ${ }^{8}$

Em suma, o Digital Audio Workstation possibilita a captura e o processamento de qualquer tipo de áudio, seja analógico, seja $\mathrm{MIDI}^{9}$, além de possuir uma enorme variedade de sons nos seus bancos de dados. Como já exposto, os DAWs conquistaram um grau de performance técnica que suplantou muitas características dos estúdios e sistemas analógicos de áudio. Alguns desses recursos são: a função undo, o automa-

8 Acesso em: 07 dez. 2015.

9 MIDI (Musical Instrument Digital Interface) é um protocolo de dados usado para transferir sons e ações para um DAW. 
tismo do cut'n'paste, que acabaram por propiciar métodos de composição baseados em grooves, os plugins de efeitos ou de instrumentos virtuais e as inovações de interfaces - tais como o touch screen - que ultrapassam o uso do teclado e do mou$s e^{10}$. Cortar e colar (cut'n'paste), mesclar e desfazer são ações triviais para quem utiliza os DAWs e suas possibilidades automáticas na criação de grooves ou loops.

Vários outros fatores sonoros podem ser criados ou modificados: forma da onda e filtragens, parâmetros como timbre, intensidade, altura, duração, transformando os sons em infinitas possibilidades. Os DAWs herdaram dos sistemas anteriores o recurso dos envelopes, uma linha processual de gráficos interativos de segmentos e de curvas sonoras que podem ser mesclados ou ajustados pontualmente, ou seja, pode-se criar ou ajustar pontos múltiplos ao longo de uma onda sonora (contemplam quatro parâmetros dinâmicos de um som - A.D.S.R.: attack, decay, sustain e release) que podem ser alterados pelo aplicativo.

Para ilustrar a discussão, iremos abordar duas versões diferentes de DAW no que tange aos problemas de interface e desempenho enfrentados pelos designers que trabalham nesse campo de especialização: o Sonar, da CakeWalk (desde 2010, com o Sonar X1) e o GarageBand, da Apple (2013). Trata-se de proposições conceituais muito distintas, pensadas para usuários com expectativas diferentes diante de um dispositivo de registro e edição de som. O Sonar requer um conhecimento prévio de preceitos sobre os DAWs, tem alta performance técnica e é utilizado nos âmbitos profissionais

10 Talvez uma das características mais gratificantes dos DAWs seja a possibilidade de desfazer uma ação prévia, o que evita erros acidentais e que se percam registros ou gravações anteriores. Se um engano é cometido, o comando undo é conveniente para mudar e reverter passo a passo os dados ao estado prévio desejado. 
da música, do design sonoro, do audiovisual, entre muitas outras prerrogativas. 0 GarageBand assenta-se num paradigma de interface particularmente intuitiva, com recursos de desempenho limitados, porém traz certos recursos de maneabilidade com instrumentos virtuais inteligentes, a exemplo de outros artefatos produzidos pelo seu fabricante, que excitam a curiosidade e a imaginação criativa musical de utilizadores iniciantes.

\subsection{Sonar}

Projetado por Rene Ceballos, o Sonar hoje apresentado em três versões (Artist, Platinum e Professional) possui pistas de áudio simultâneas ilimitadas, pistas de áudio MIDI ilimitadas, efeitos de áudio em tempo real ilimitados, resolução MIDI 960 ppqn, efeitos MIDI (em tempo real, ilimitados), qualidade de CD estéreo ou em DVD com formatos surround compatíveis; mais de 4GB de loops, arranjados como kits construídos em vários estilos musicais. Comporta plugins com efeitos, mixagem, equalização e masterização. Ele é atualizado anualmente e seu manual de utilização possui quase 1200 páginas no formato impresso, o que atesta sua complexidade e capacidade técnica.

Tal como os DAWs profissionais em geral, o Sonar tem um layout que inclui controles com configurações padronizadas, como play, record, fastforward e rewind mapeadas de acordo com a direção das ações de sistema de áudio eletrônicos tradicionais. As trilhas de áudio possuem controles individuais, tais como volume e encadeamento de efeitos sonoros. Cada pista simples, em forma estéreo ou mono, designa o som registrado (instrumento, vozes e samples) e é mostrado se- 
paradamente, em três modos visuais: como ícone de ondas sonoras, como unidades geométricas alinhadas numa representação de um teclado vertical ou numa partitura musical. Os comandos disponíveis na interface permitem operar as trilhas como normalmente se faz numa mesa de mixagem, sendo que as características individuais de cada trilha podem ser ajustadas de forma independente, permitindo-se agrupá-las para quaisquer experimentações sonoras.

O Sonar possui uma interface visual, reproduzida na imagem 2, que combina elementos monocromáticos, coloridos, em 2D ou 3D, além da opção de customizar as cores do display. Os recursos básicos de controle em sua interface, como chaves, botões, potenciômetros e controles deslizantes são similares aos demais DAWs. Por meio do rolamento do mouse pode-se, por exemplo, maximizar, minimizar ou restaurar botões de controle, tornando possível alterar-se a visibilidade muito rapidamente. ${ }^{11}$

11 Para determinadas ações (arrastar, rolar e manejar potenciômetros), o uso do mouse é o mais indicado, pela velocidade e facilidade gestual. 0 seu uso constante, muitas vezes, força movimentos de pulso, cotovelo e ombros, fato que são pensados pelos designers de modo a simularem ao máximo uma experiência gestual e ergométrica diante de um console de estúdio de gravação físico. Basicamente todas as operações podem ser realizadas por meio de atalhos do teclado, desde as funções de transporte (play, record, etc.) até o cut'n'paste. 
Imagem 2 - Interface visual do Sonar

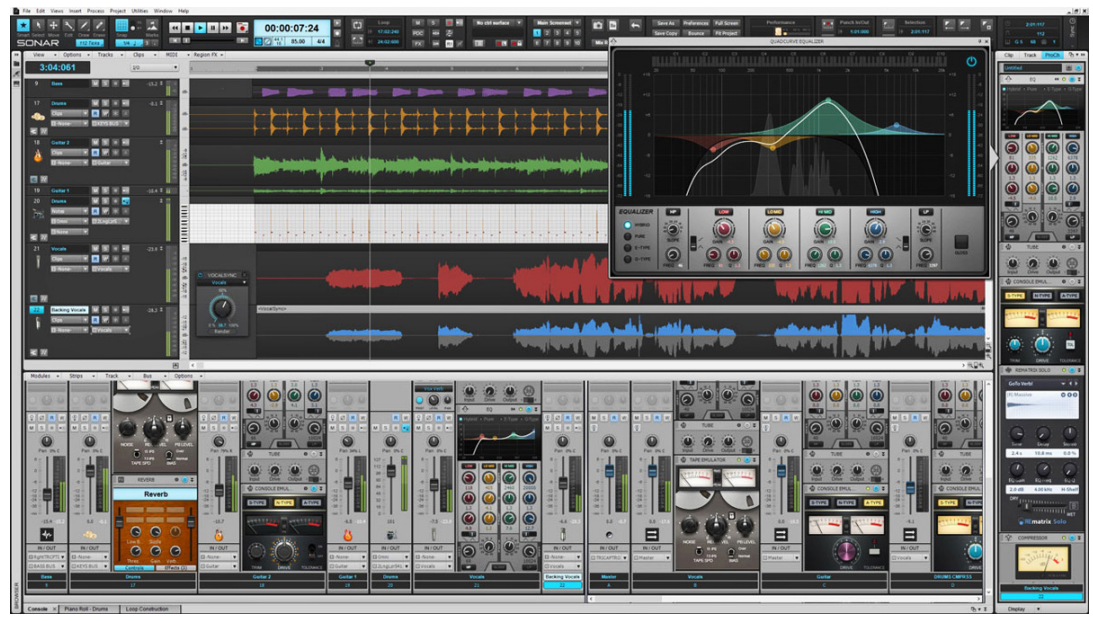

Fonte: CakeWalk (www.cakewalk.com) ${ }^{12}$

Os controles de superfície permitem expor, simultaneamente, todas as faixas com canais de áudio em uso ou apenas aquelas que se deseja visualizar. Pode-se aumentar instantaneamente as faixas de áudio individuais ou recolher as demais a uma altura minúscula, definida pelo título (pode-se definir as faixas individuais para qualquer tamanho arrastando os divisores horizontais entre cada uma delas ${ }^{13}$ ). Ao aumentar o zoom, mais faixas horizontais aparecem no painel de pistas de áudio contendo muitos outros parâmetros. Na parte superior do painel de pistas há uma barra de ferramentas com botões

12 Acesso em: 07 dez. 2015.

13 Ao arrastar o divisor vertical entre os painéis de trilha e de clipe (trecho recortado da pista de áudio), vários parâmetros redimensionam-se e reorganizam-se para atender à nova largura disponível. As faixas de áudio têm Volume, Pan, e Trim, entrada e saída de roteamento para efeitos (plugins em tempo real e instrumentos virtuais), e um conjunto de comutações Pan (panorama estereofônico), pré-fader e pós-fader ou controles de fase das ondas sonoras. 
para selecionar todas as faixas, um gerenciador de módulo para decidir quais faixas serão exibidas, as opções para alternar a exibição de gravação e reprodução de medição definidos pelo usuário para cada faixa de áudio individual, bem como ferramentas de áudio e os envelopes sonoros.

O Sonar contempla também múltiplas manipulações sonoras minuciosas, como distorção, reverberação e eco, efeitos de chorus, phaser eflanger, limiter, compressor, sintetizadores digitais, instrumentos e amplificadores virtuais. Esses plugins podem ser usados em camadas e automatizados, modelando sons em novos samples (amostras sonoras).

Quando se clica no ícone ativar looping, o Sonar corta automaticamente o clipe em uma série de beats definidos por marcadores, podendo ajustá-los, arrastando-os. Ao clicar duas vezes em um sulco do clipe, uma janela de Construção de Loop se abre. O Sonar vem com o Aim Assist Line, uma ferramenta que permite mover clipes visualmente por meio de reposicionamentos, retornando na linha de tempo ou colocando-os à frente da posição inicial. Utilizando o mouse, seus movimentos são precisamente mostrados na linha de medida do tempo. Com outro aplicativo, o Loop Explorer 2.0, pode-se arrastar visualmente clipes de grooves ou patterns de ritmos (células rítmicas), sejam MIDI, sejam analógicos, para a pista de áudio.

\subsection{GarageBand}

O GarageBand, por sua vez, é uma ferramenta que prima por ser altamente intuitiva, de fácil aprendizado, e conta com grupos de instrumentos virtuais de alta resolução e dinamismo visuais, um arquivo restrito de sons, loops, amos- 
tras sonoras. Um aplicativo como este, como já sugere o nome ("banda de garagem") é voltado para músicos iniciantes, diletantes ou mesmo para compositores experientes, mas não afeitos às dificuldades técnicas de interação com os DAWs mais sofisticados em seu processo de criação. Músicos profissionais utilizam o GarageBand para registrar as suas ideias e depois migram para outros softwares, deixando ao encargo de técnicos de som o trabalho mais específico de edição e arte final. Ao que parece, o aplicativo privilegia a guitarra elétrica como instrumento principal a ser utilizado, uma vez que não é oferecida virtualmente, apenas amplificadores a serem ligados ao instrumento real via input.

0 GarageBand roda nos dispositivos iOS (iPad, iPhone - como mostra a imagem 3), apenas no Mac. Tem somente entradas de áudio para plugins, não possuindo mesa de mixagem nem exportação de MIDI. 0 aplicativo é dotado de loops produzidos pela Apple Loops. Alguns parâmetros, no entanto, não podem ser alterados durante a execução de playback. 
Imagem 3 - Interface do GarageBand para iPhone

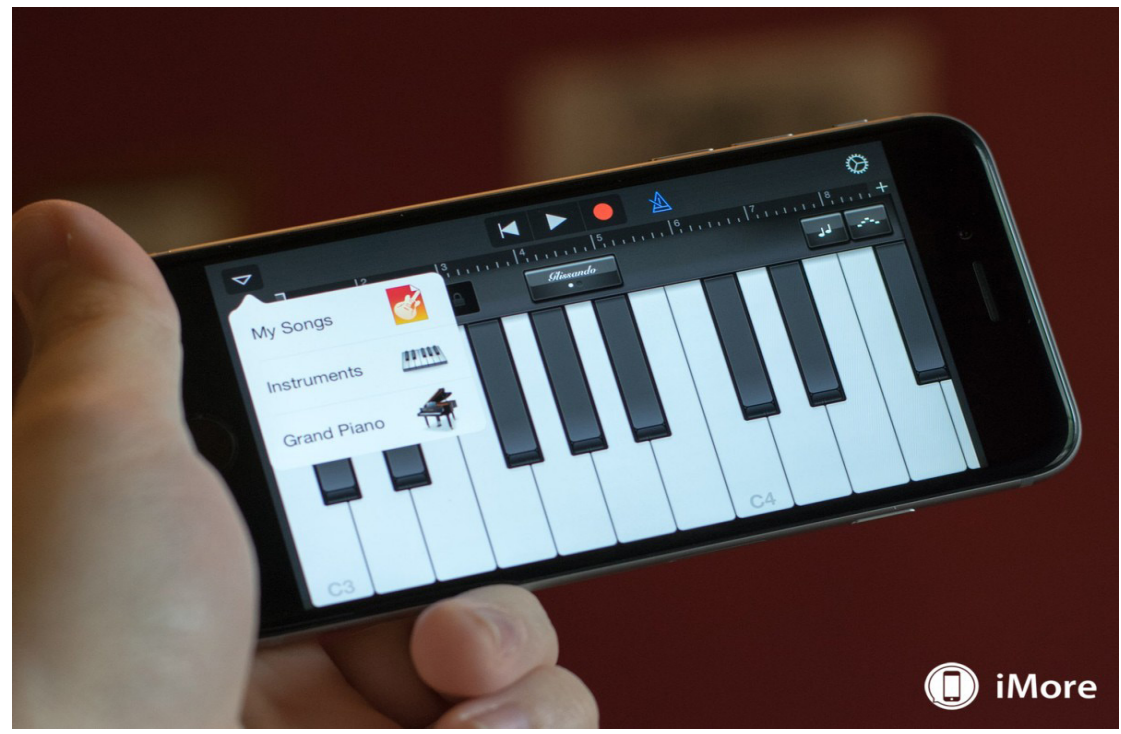

Fonte: Macworld (www.macworld.com) $)^{14}$

Como utiliza o paradigma de interface touch screen, bastante desenvolvido nos artefatos da Apple, o GarageBand proporciona uma sensação mais direta de maneabilidade e affordance nos controles básicos das ações. A partir de comandos icônicos e em 3D, com textura, brilho e definição visual impecáveis, definem-se alguns instrumentos virtuais disponíveis, tais como "sampleadores" e sequenciadores (smart keyboard e smart drums), além do microfone de voz com recursos de efeitos. Dispondo de comandos básicos escritos, o utilizador migra de uma seção para a outra: de "Instrumentos" vai-se

14 Acesso em: 07 dez. 2015. 
para a seção "Minha Música”, com barra de ferramentas e cursor com régua de compassos, na qual tudo é gravado e aparece numa pista horizontal. Ao se iniciar o aplicativo, abre-se um navegador que apresenta horizontalmente uma sequência de ícones para cada instrumento (amplificador de guitarra, violão, contrabaixo, piano, cordas, bateria), microfone de voz e "sampleador", estando à escolha por meio de gestos deslizantes dos dedos na tela, para a esquerda ou para a direita. Ao tocar com os dedos sobre cada ícone, abre-se uma interface com superfícies executáveis do instrumento selecionado.

\section{Imagem 4 - Interface visual do GarageBand}

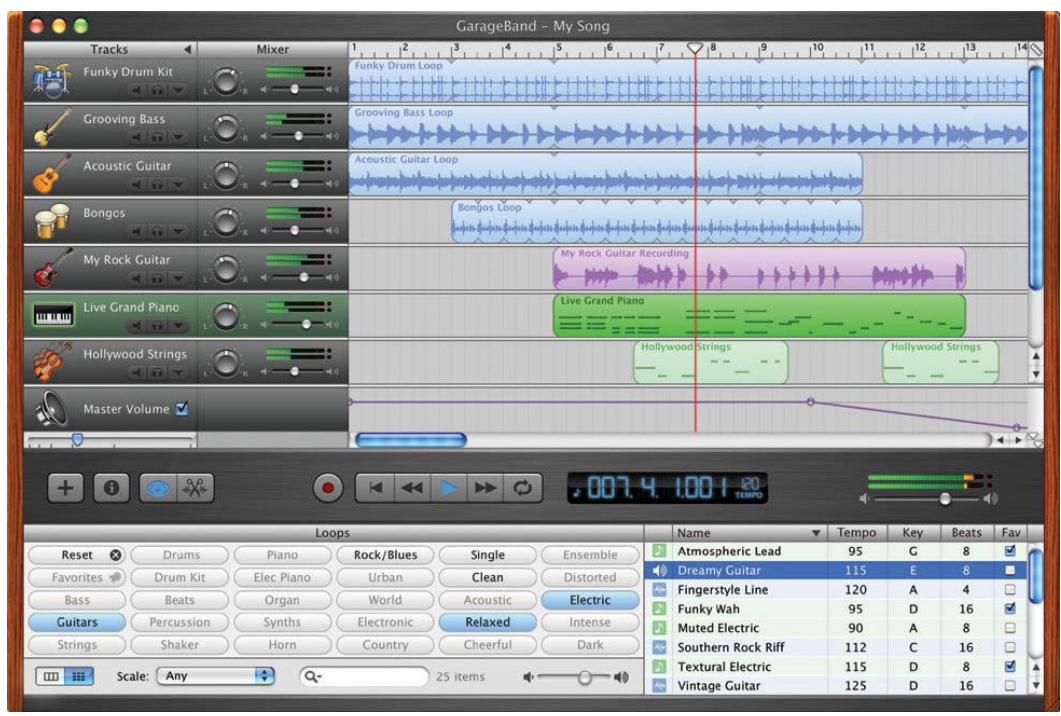

Fonte: Macworld (www.macworld.com) $)^{15}$ 
Como pode ser visto pela imagem 4 , a tela é dotada de três partes: a área de execução instrumental touch screen, a área de controle (funções de transposer, glissando, modulação, arpegiador, escalas, afinador, volume, velocidade) e uma barra de ferramentas com a régua do cursor de tempo.

A página apresenta uma janela com alguns modelos específicos e mais conhecidos (por exemplo, contrabaixos elétricos das marcas Hofner, Rickenbaker, Fender) do respectivo instrumento. 0 GarageBand oferece uma interface de execução instrumental muito interessante, porque mescla o conhecimento prévio que se tem usualmente sobre cada instrumento e acrescenta soluções diferentes para executá-lo em conformidade com as possibilidades do touch screen (como mostra a imagem 5) e das técnicas digitais de intervenção sonora. Além disso, nota-se um hiper-realismo dinâmico, visual e sonoro sobre as execuções dos instrumentos (tridimensionalidade, visualidade verossímil das vibrações das cordas ao serem tocadas, texturas, mudanças de timbre sonoro conforme a intensidade do toque, etc.). 
Imagem 5 - Representação do Touchscreen no GarageBand

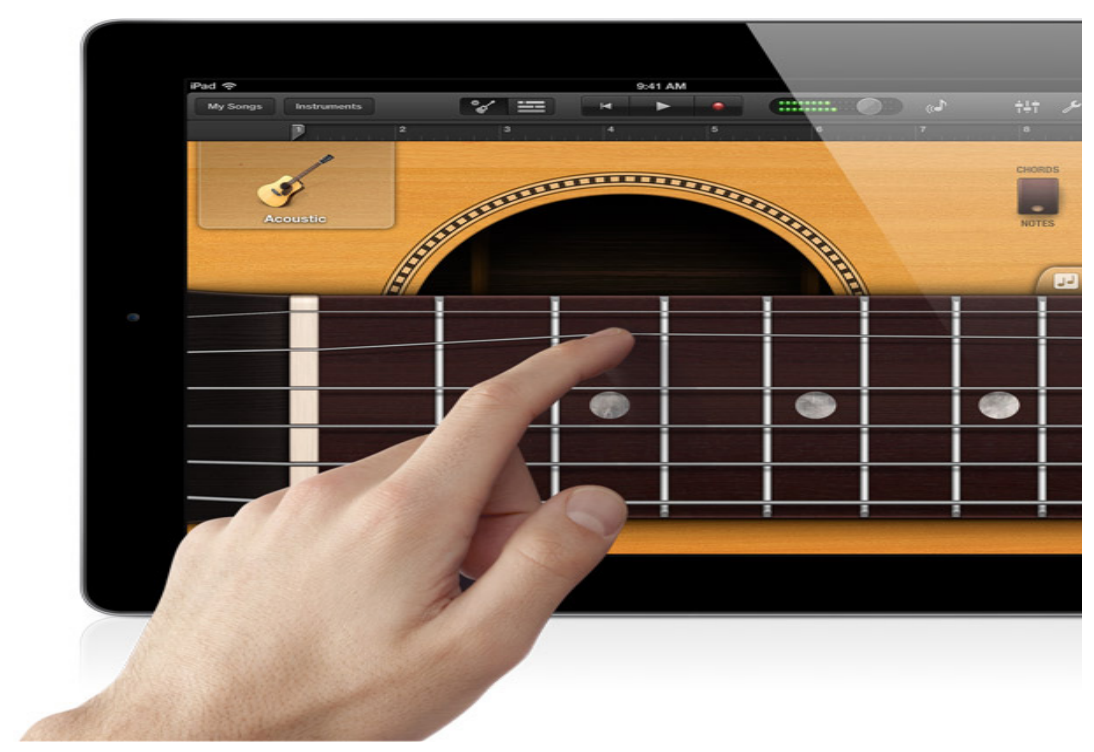

Fonte: Macworld (www.macworld.com)

\section{Considerações finais}

No percurso desenvolvido por este artigo, foram apresentados os problemas enfrentados pelo processo do design de interfaces e o modo como os estudos da semiótica sobre os conceitos de experiência e de metacomunicação podem auxiliar nos pontos de partida conceituais de um trabalho criativo que precisa levar em conta a experiência de interação digital. Foram considerados, no projeto de cada DAW aqui comentado, os potenciais usuários do sistema (usuário arquetípico) e o contexto de uso (cenários culturais nos quais o sistema será empregado).

Ao projetar um design de interfaces, pressupõe-se uma 
prospecção da expectativa do utilizador e do seu sentimento de apropriação performática. Pautando-se na imaginação de uma experiência a priori, o designer alcançaria, para a interação, uma outra experiência satisfatória, conseguindo, ao mesmo tempo, promover estágios para novas conversações? Um projeto de design de interação com interfaces deve, por fim, mapear tanto aspectos físicos e sociais quanto estéticos e afetivos. Por isso, a forma como uma interface é projetada, para além de auxiliar o nosso modo de perceber, de aprender e de lembrar como realizamos tarefas no engajamento com os sistemas e dispositivos digitais, pode afetar a nossa experiência mesma do mundo e, no caso específico aqui abordado, a própria experiência da criação e da escuta musical.

No que concerne à dimensão da experiência - sensações, memórias, afetos, percepção, apreensão intelectual, surpresas e esperas - de quem se envolve com ambos os DAWs estudados, o Sonar e o GarageBand, resguardadas as distinções entre eles, muitos métodos de composição musical são desestabilizados e, com isso, provocam a imaginação do utilizador a experimentar conexões diferentes entre suas ideias sonoras e musicais. Diante da nova realidade propiciada pelos DAWs, coloca-se, para o pesquisador, outra indagação a ser objeto de investigação futura: com tais prerrogativas, será que outras circunstâncias de criação passariam a surgir e poderiam provocar mudanças para a fantasia sonora do compositor?

\section{REFERÊNCIAS}

BUYDENS, M. Sahara, l'Estétique de Gilles Deleuze. Paris: J. Vrin, 1990. 
DE SOUZA, C. The Semiotic Engineering of Human Computer Interaction. Cambridge, MA: MIT Press, 2005.

FERRAZ, S. Música e repetição. São Paulo: Educ, 1998.

PEIRCE, C. S. Semiótica. São Paulo: Perspectiva, 1987.

PREECE, J.; ROGERS, Y.; SHARP, H. Design de interação: além da interação homem-computador. Porto Alegre: Bookman, 2005.

STEINERT, S. Interfaces: crosslinking humans and their machines. International Journal of Applied Research on Information Technology and Computing, v.1, n.1, p. 130140, 2010.

Artigo recebido em dezembro de 2015 e aprovado em abril de 2016.

\section{Como citar este trabalho:}

RODRIGUES, Rodrigo Fonseca e; CARDOSO, Ana Maria Pereira. A experiência da interação e o design de interfaces: semiótica e metacomunicação nos Digital Audio Workstations. CASA: Cadernos de Semiótica Aplicada, São Paulo, v. 14, n. 01, p. 265-290, julho, 2016. Disponível em: <http://seer.fclar. unesp.br/casa>. Acesso em "dia/mês/ano". http://dx.doi. org/10.21709/casa.v14i1.8244. 